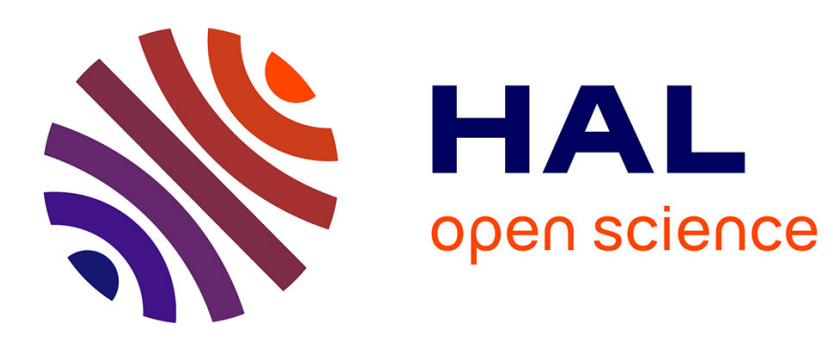

\title{
Evaluation of chloride contamination in concrete using electromagnetic non-destructive testing methods
}

Xavier Derobert, Jean-François Lataste, Jean Pierre Balayssac, S. Laurens

\section{To cite this version:}

Xavier Derobert, Jean-François Lataste, Jean Pierre Balayssac, S. Laurens. Evaluation of chloride contamination in concrete using electromagnetic non-destructive testing methods. NDT \& E International, 2017, 89, pp.9-29. 10.1016/j.ndteint.2017.03.006 . hal-01596683

\section{HAL Id: hal-01596683 \\ https://hal.science/hal-01596683}

Submitted on 28 Sep 2017

HAL is a multi-disciplinary open access archive for the deposit and dissemination of scientific research documents, whether they are published or not. The documents may come from teaching and research institutions in France or abroad, or from public or private research centers.
L'archive ouverte pluridisciplinaire HAL, est destinée au dépôt et à la diffusion de documents scientifiques de niveau recherche, publiés ou non, émanant des établissements d'enseignement et de recherche français ou étrangers, des laboratoires publics ou privés. 


\section{Evaluation of chloride contamination in concrete using electromagnetic non-}

\section{Abstract}

12 We present the results of the sensitivity of some electromagnetic non-destructive testing 13 (NDT) methods to chloride contamination. The NDT methods are resistivity, using a

14 quadripole probe, capacitive technique, with few sets of electrodes, and radar technique,

15 using different bistatic configurations. A laboratory study was carried out involving

16 three different concretes with different water to cement ratios. The concretes were

17 conditioned with different degrees of $\mathrm{NaCl}$ saturation by means of three solutions

18 containing $0 \mathrm{~g} / \mathrm{L}, 30 \mathrm{~g} / \mathrm{l}$ or $120 \mathrm{~g} / \mathrm{l}$. The solution was homogenized in the concrete by 19 using a specific procedure. Results show that the EM techniques are very sensitive to

20 the chloride content and saturation rate and, on a second level, to the porosity. Multi-

21 linear regression processing was performed to estimate the level of sensitivity of the

22 NDT measurements to the three indicators. Values of ten ND observables are presented

23 and discussed. At last, the uncertainties of the regression models are studied on a real

24 structure in a tidal zone.

25 Keywords: radar, resistivity, capacitance, humidity, concrete, chloride, measurement 
26 uncertainty

\section{Introduction}

28 Chloride-induced corrosion is one of the major causes of degradation of reinforced

29 concrete structures, considering marine exposure conditions or the extensive use of de-

30 icing salts in many countries. Reliable assessment of existing structures is based on the

31 knowledge of chloride concentration values, as the residual service life is estimated

32 from the time required to reach the chloride threshold value at the depth of the

33 reinforcement [1-3].

34 Although the destructive characterization of chloride content is now fully applied all

35 over the world, it is widely recognized that the procedure is cumbersome and requires a

36 lot of time, and that any non-destructive technique able to provide this information

37 would bring an appreciable improvement to the assessment methodologies [4]. The

38 complexity of the diagnosis is partially due to the multiple influences included during

39 the measurement and the inversion process, all of which act as sources of uncertainty in

40 the diagnosis. Generally, to assess an indicator (e.g. chloride content), all other

41 properties are assumed to be constant. This assumption is either justified - and the

42 diagnosis is accurate - or false - but the approach is still used for lack of another

43 solution. The latter case is the more frequent, which is why improvements to NDT

44 methods and interpretation methodology are long overdue.

45 Numerous studies have shown the great potential of electromagnetic (EM) techniques,

46 including electrical ones, for the evaluation of concrete durability indicators, such as

47 water content, chloride content and, to a lesser extent, porosity [5-12]. These studies,

48 performed on different concrete mixes, have shown the high level of sensitivity of the

49 EM observables (from conductivity to relative permittivity at radar frequencies) to these 
50 durability indicators.

51 A national project gathering six academic partners and six industrials, the "Strategy of

52 non-destructive evaluation for the monitoring of concrete structures” (SENSO) project,

53 aimed to propose a methodology for the non-destructive evaluation of some indicators

54 related to the durability of concrete by means of a combination of numerous non-

55 destructive testing (NDT) methods, including electrical, EM and ultra-sonic (US)

56 techniques [13]. For each indicator, the objectives were to evaluate its value (average

57 and degree of variability) and to estimate the degree of reliability of this evaluation. An

58 important experimental study was carried out on controlled samples (homogeneous

59 regarding the variation of indicators inside the samples) and a large database was built

60 up and explored to draw relationships between NDT measurements and indicators [13-

61 16]. Saturation rate, porosity, carbonation depth and chloride ingress were the indicators

62 addressed for 8 different concrete compositions, and were investigated with more than

6311 ND methods.

64 Within that framework, a specific experimental programme was dedicated to chloride

65 content, and the objective of this paper is to present the results of that study. Laboratory

66 experiments were carried out on three different concretes using three saturation degrees

67 of solutions involving two concentrations of $\mathrm{NaCl}$ (30 and $120 \mathrm{~g} / \mathrm{l}$ ). The quantities of

68 total chloride were assessed by chemical titration and NDT measurements were

69 performed at the same time. As US techniques showed very low sensitivity to chloride

70 content, only the electrical and EM techniques are presented and discussed below.

71 In this paper, the objective of the first study is to determine multilinear regressions

72 between ND measurements and specific indicators: saturation rate, porosity and

73 chloride content, for various depths, on controlled concrete samples. The second part 
74 studies the use of these regressions to estimate chloride content, also addressing the

75 question of uncertainty at the levels of methods and models. Then, the last part is

76 devoted to their implementation on a real site in a tidal zone. The discussion only

77 focuses on the choice of techniques for chloride contamination diagnosis here, and on

78 the uncertainty levels.

79

80 2. Experimental design

\section{2.1. Preparation and conditioning of concretes}

82 Focusing on chlorides, three concretes were made using the same cement (CEMI $52.5 \mathrm{~N}$

83 from Calcia) and the same nature of aggregates (round siliceous) from the River

84 Garonne. The details are presented in Table 1, keeping the same references as those used

85 in the SENSO project [13]. For each mix, 11 slabs $(50 \times 25 \times 12 \mathrm{~cm})$ were cast and water

86 cured for 28 days. Three of these slabs were devoted to assessment of the porosity, the

87 compressive strength and the characterization of the Young's modulus.

88

Table 1. Concrete characteristics

\begin{tabular}{lccc}
\hline Aggregates & \multicolumn{3}{c}{ Round Siliceous (0/20 mm) } \\
Reference & G1 & G3 & G8 \\
W/C & 0.30 & 0.55 & 0.80 \\
Cement (kg/m ${ }^{3}$ ) & $405^{*}$ & 370 & 240 \\
$\mathbf{2 8}$ day strengh (MPa) & 72.9 & 43.8 & 20.2 \\
Density (kg/m ${ }^{3}$ ) & 2541 & 2457 & 2405 \\
Porosity (\%) & 12.5 & 15.5 & 18.1 \\
\hline \multicolumn{2}{c}{$*$ addition of $45 \mathrm{~kg} / \mathrm{m}^{3}$ of silica fume } \\
\end{tabular}

90 The other 8 slabs were contaminated with different concentrations of chlorides. After

91 drying at $80^{\circ} \mathrm{C}$ until their weight became constant, 4 slabs were contaminated by

92 absorbing a solution of water containing $30 \mathrm{~g} / \mathrm{l}$ of $\mathrm{NaCl}$ (CL-1) at three different

93 saturation degrees (one slab at $40 \%$, one slab at $80 \%$ and two slabs at $100 \%$ ). The other 
944 slabs were contaminated with a solution of water containing $120 \mathrm{~g} / \mathrm{l}$ of $\mathrm{NaCl}$ (CL-2) in

95 the same conditions of saturation. After absorbing the quantity of salt water

96 corresponding to a given saturation degree, each slab was sealed in a polyethylene sheet

97 and adhesive aluminium foil.

98 They were then placed in an oven at $80^{\circ} \mathrm{C}$ for three months to homogenize the

99 interstitial solution. Before the contamination with chlorides, the slabs were conditioned

100 at 5 different levels of saturation $(0,40 \%, 60 \%, 80 \%$ and $100 \%$ of tap water) and tested

101 with NDT methods in the same conditions as for chloride contamination (CL-0). Thus it

102 was possible to compare the effect of chloride contamination on NDT measurements on

103 the sample samples. Table A1, in appendix, summarizes the saturation rate for all the

104 concretes, the porosity (measured on only 1 slab) and the total chloride content in

105 percentage weight of dry concrete, assessed by chemical titration at different depths (5,

10610,15 and $20 \mathrm{~mm}$ ). It can be seen that there was no significant chloride gradient over

107 the depth investigated by titration.

108

109 2.2. NDT measurements

110 Radar technique

111 The radar techniques developed in the framework of this study relied on commercial

112 ground-penetrating radar (GPR) systems, using SIR-3000 systems from Geophysical

113 Survey Systems Inc. (GSSI ${ }^{\circledR}$ ) and two separate ground-coupled $1.5 \mathrm{GHz}$ antennas. Two

114 approaches were employed. One of them used four offsets (transmitter-receiver 115 distance), ranging from 7 to $14 \mathrm{~cm}$, with an absorbing sponge placed between the

116 transmitter and the receiver, in order to measure the direct wave in the medium without

117 distortion due to the direct air wave [16]. Few observables were studied with this 
118 configuration: the velocity, the corresponding relative permittivity and the attenuation

119 from the direct wave, and the arrival time for the largest offset. For the attenuation, the

120 observable studied corresponded to the slope coefficient of the logarithm of the

121 amplitudes.

122 The second approach, with one standard $1.5 \mathrm{GHz}$ antenna, directly measured the peak-

123 to-peak amplitude of the direct wave in the medium [6-7]. This amplitude was

124 normalized to the peak-to-peak amplitude of the signal in air. For both configurations,

125 the coupled thickness of the medium, in the near vicinity of a GPR antenna which

126 interacts with it, can be estimated at $8-10 \mathrm{~cm}$.

127

128 Capacitive technique

129 This technique, and the corresponding sensor, was designed by the network of

130 laboratories of the Ministry of Ecology, Sustainable Development and Energy (France)

131 and tested in reinforced concrete structures [16-18]. The principle of the capacitive

132 technique is to measure the resonance frequency of an oscillating circuit (around 30-35

$133 \mathrm{MHz}$ ) between several electrodes lying on the upper face of the concrete slab. A

134 calibration allows the concrete relative permittivity $\varepsilon_{\mathrm{r}}^{\prime}$ to be obtained, which is mainly

135 related to the water content and the mixture components. The volume investigated

136 depends on the geometry of the electrodes (coupled depth of roughly 1-2 cm for

137 medium sized electrodes - ME - and 6-8 cm for large electrodes - GE).

139 Resistivity technique

140 The technique tested in this study used a four-probe square device that injects electrical

141 current between two lateral probes and measures the potential difference between the 
142 other two probes [18-20]. The apparent resistivity is deduced from the ratio of the

143 potential to the intensity, according to the geometrical characteristics. Measurements,

144 with two spacings (5 and $10 \mathrm{~cm}$ ), were performed for two orthogonal directions of

145 electrical current injection and then averaged, for coupling thicknesses of about 3 and 6

$146 \mathrm{~cm}$ respectively. For an accurate analysis, given the wide range of variation of resistivity

147 between concretes in different states of moisture and chloride content, it is necessary to

148 study the resistivity in its logarithmic form ( $\log (\operatorname{Res}))$.

149 In the following text, the term "observable" will be used as a generic term for all the ND

150 studied observables (Table A2, in appendix).

\section{Laboratory results}

153 The first campaigns in the SENSO project showed that most of the NDT techniques

154 tended to give results that varied linearly with the indicators. As the EM techniques are 155 sensitive to both water and chloride content, and indirectly to the porosity, some 156 regression functions to one indicator can only be proposed when the other two are 157 constant. The data were processed to fit a multi-linear regression (3-parameter) function 158 on the three indicators, under the hypothesis of averaged values without depth gradient.

159 Equation 1, for the GPR velocity, is presented as a model equation:

$$
\text { Velocity }_{G P R}=a \cdot \text { Poro }+b \cdot S_{r}+c \cdot C l^{-}+d
$$

161 where Poro, $S_{r}$ and $\mathrm{Cl}^{-}$correspond to the porosity, the saturation rate and the chloride

162 content, respectively, and $a, b, c$ and $d$ to the multi-linear regression coefficients.

163 Some ND observables require specific adaptation, such as the GPR signal attenuation 164 and the resistivity measurements. Concerning the electrical resistivity, for concrete, as 165 for porous materials, the empirical Archie’s law is used and expressed as: 
167 where the porosity, Poro, and the saturation, Sr, are clearly factors influencing the

168 resistivity $R$, and where the influence of chloride is represented through the interstitial

169 fluid resistivity $\left(R_{w}\right)$. Expressed in logarithmic terms, the law becomes:

$$
\log R=\log a-m \cdot \log \text { Poro }+\log R_{w}-n \cdot \log S_{r}
$$

171 where, considering the range of variation for porosity (12 to 18\%) and saturation (40 to 172 100\%), we can accept that Log Poro and $\log S_{r}$ are proportional to Poro and $S_{r}$, 173 respectively. For $\mathrm{Cl}^{-}$, a link with $R_{w}$ also exists [21-22]. Finally, the linear regression 174 approach chosen (Eq. 1), is very comparable with the well known Archie's law for 175 resistivity; and $a, b, c$ and $d$ are indicators of $a, m$, and $n$ of the Archie's law. Similarly, 176 as the GPR attenuation is exponential through its propagation in a medium, a 177 logarithmic approach enables the model equation shown in Eq. 1 to be used.

178 Figure 1 presents, through the example of the GPR velocity, the dispersion of the 179 measurements when only one indicator is considered (Fig.1a-b), or when two or the 180 three indicators are considered through the modelling of the velocity using the muli181 linear regression coefficients from Equation 1 in Figures 1c-d. We note that the 182 determination coefficient $\mathrm{R}^{2}$ is not significant $(<0.7)$ for the simple regressions (Figs 183 1a-1b) but it increases notably to 0.83 for a 2-parameter regression on $S_{r}$ and $\mathrm{Cl}^{-}$ 184 (Fig.1c), and rises to 0.89 for the last case (Fig. 1d), showing that it is necessary to take 185 all of these three indicators into account.

186 From a statistical point of view, the threshold chosen for a test of significance is defined 187 by the Student law, for 33 samples and a $97.5 \%$ confidence interval. This test, applied to 188 the chloride content coefficient, showed that the ratio of the coefficients, $c$, to their 189 standard-deviations $\sigma_{c}$, calculated by the multi-regression (3-parameters), had to remain 
190 above the threshold 2.037.

191 With this approach for each ND method, the coefficients of the regression were assessed

192 as a function of porosity, saturation rate, and chloride content. For all the EM ND

193 techniques, values depended on the chloride contents assessed at different depths $(5,10$,

194 15, $20 \mathrm{~mm}$ and average). Table 2 summarizes the values obtained in the test of

195 significance. The results confirm that all the EM ND techniques are sufficiently

196 sensitive and reliable as far as the estimation of the chloride content is concerned. We

197 note that the highest values (in bold in the table) are obtained when the depth of the

198 estimation of the chloride content tends to the coupled volume of the ND technique.

a)

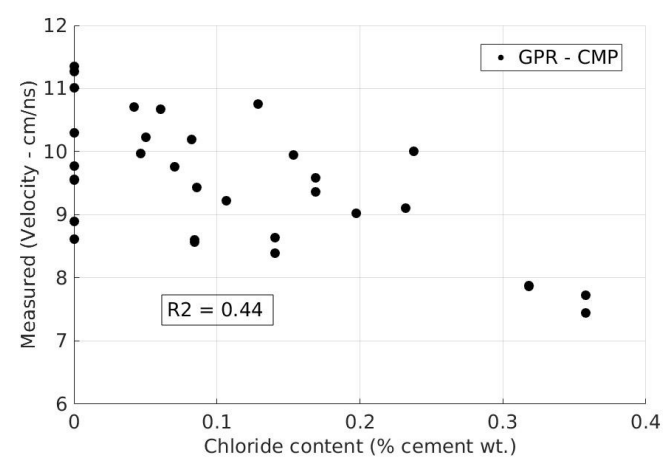

c)

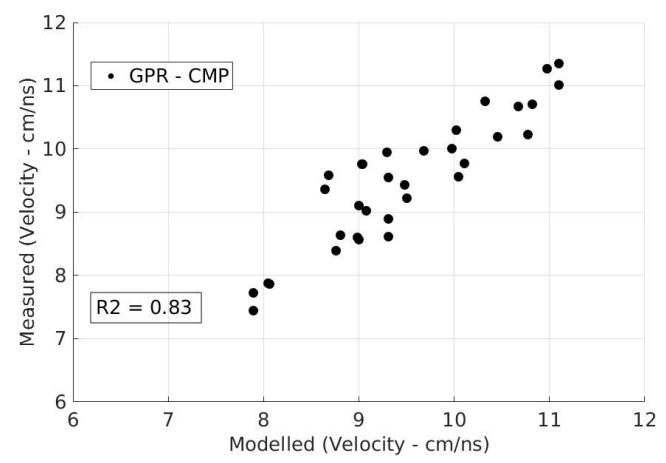

b)

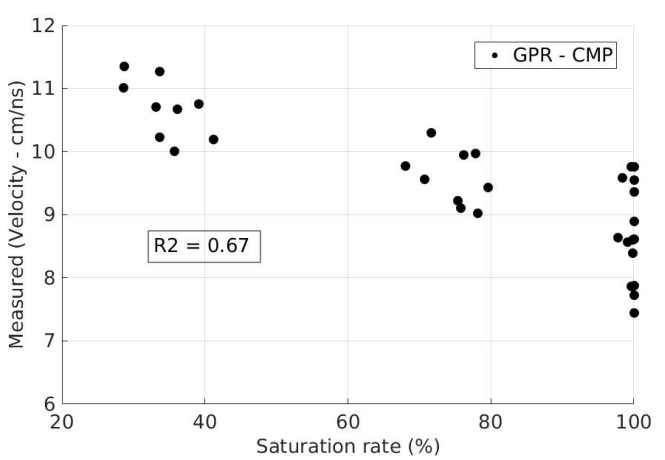

d)

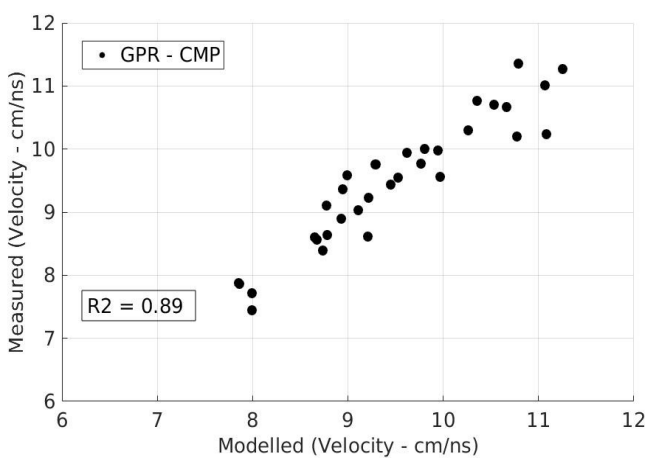

199 Fig. 1. GPR velocity measurements, obtained by CMP, as a function of a) the chloride content,

200 b) the saturation rate, c) the GPR velocity modelled using the 2-parameter regression $\left(S_{r}\right.$ and $\left.\mathrm{Cl}^{-}\right)$, d) the $\mathrm{GPR}$ velocity modelled using the 3-parameter regression $\left(\mathrm{S}_{r}, \mathrm{Cl}^{-}\right.$, Poro $)$

202 Table 3 shows the regression coefficients obtained by keeping the case (depth for 203 estimation of chloride content) leading to the best value in the test of significance, for 
each technique.

205 The values of the coefficients of the indicators, corresponding to Equation 1 and 206 presented in Table 3, enable the ND measurements to be linked to the modelled ones.

207 Some examples of modelling (one per technique) are shown in Figure 2. Their 208 coefficients of determination $\left(\mathrm{R}^{2}\right)$ vary from 0.67 for the GPR (Time Offset-L parameter 209 observable) to 0.78 for the capacitive technique (LE), values which increase to above 2100.8 when removing one apparent outlier. These results show that, even if the chloride 211 contents are not perfectly constant versus depth in the mixes, the multi-linear regression 212 remains efficient to estimate $\mathrm{Cl}^{-}$, while taking $S_{r}$ and Poro into account. Table 2. Values obtained in test of significance, applied to the $\mathrm{Cl}^{-}$coefficient, for the ND techniques according to the chosen total chloride content (at 5, 10, 15 and $20 \mathrm{~mm}$ and average)

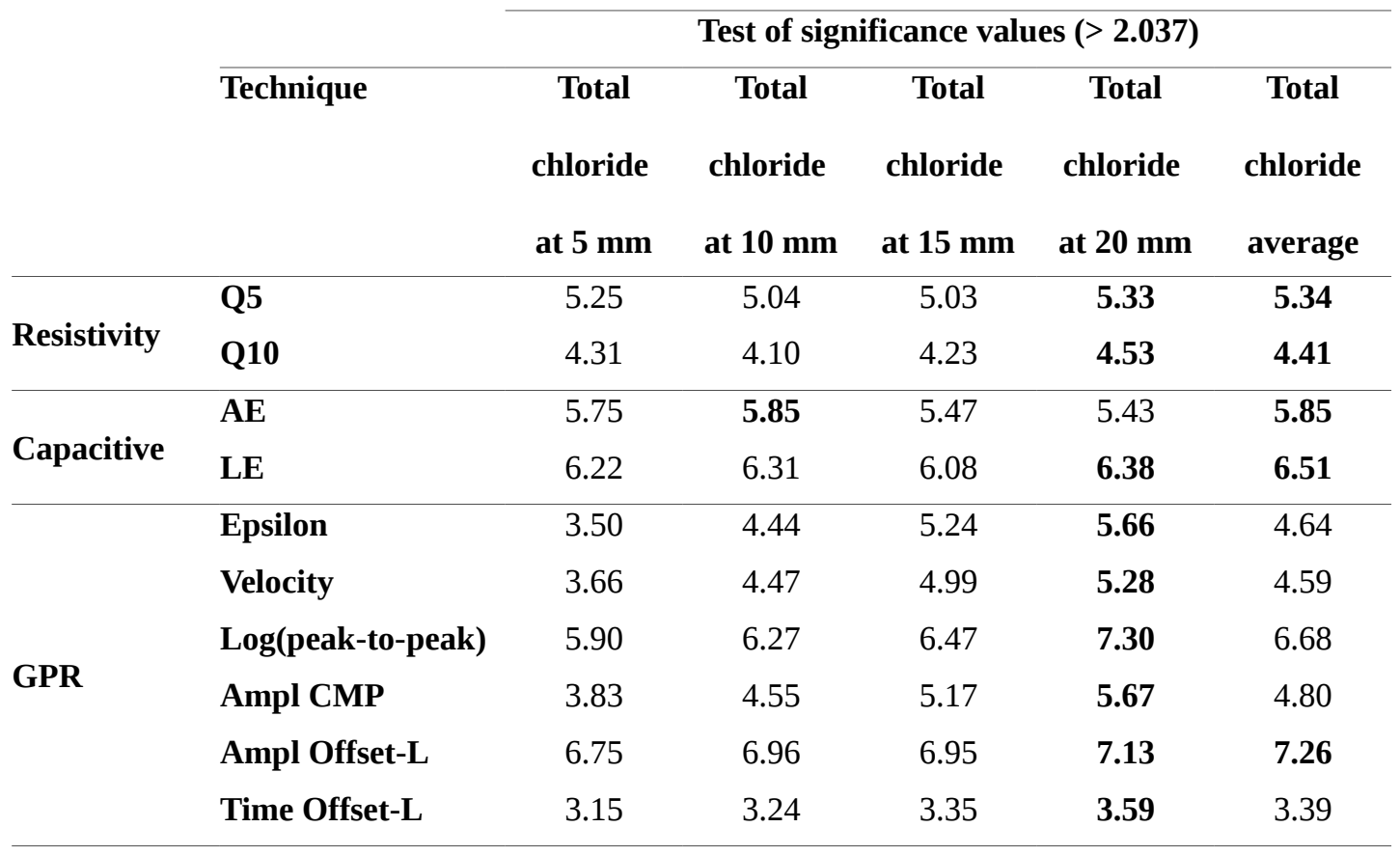

216 It is interesting to note that Hugenschmidt and Loser [8] obtained very similar values,

217 about 0.81 for the GPR attenuation (in logarithmic units), versus $\mathrm{Cl}^{-}$, using air-coupled 2

218 GHz echoes on concretes containing chlorides. These values are close to our coefficient 219 of 0.77 for $\mathrm{Cl}^{-}$for the GPR log (peak-to-peak) observable. Sbartaï \& al. [23] also found 
220 similar results, with a value of about 0.74 , for the coefficient related to $\mathrm{Cl}^{-}$, using

221 ground-coupled GPR antennas at $1.5 \mathrm{GHz}$ and a normalized reflected echo (in

222 logarithmic units), on homogeneous concrete slabs having 14-15\% porosity. This

223 means that several distinct and independent studies have led to the same reliability for

224 attenuation versus chloride content. This may be considered as a classical dependency.

225 Nevertheless, there is no discussion of uncertainties in these papers.

Table 3. Coefficient of the multi-regressions of the ND techniques performed in their optimal configuration of chloride content (correponding to the greatest $\mathrm{a} / \sigma_{a}$ )

\begin{tabular}{|c|c|c|c|c|c|c|c|}
\hline & & \multicolumn{6}{|c|}{ Coefficients } \\
\hline & \multirow[b]{2}{*}{ Techniques } & \multirow{2}{*}{$\begin{array}{c}\text { Coef. } \boldsymbol{a} \text { for } \\
\text { Poro }\end{array}$} & \multirow{2}{*}{$\begin{array}{c}\text { Coef. } \boldsymbol{b} \text { for } \\
S_{r}\end{array}$} & \multirow{2}{*}{$\begin{array}{c}\text { Coef. } \boldsymbol{c} \text { for } \\
\mathrm{CI}^{-}\end{array}$} & \multirow[t]{2}{*}{ Coef. $d$} & \multirow[t]{2}{*}{$\mathbf{R}^{2}$} & \multirow{2}{*}{$\begin{array}{l}\text { Chloride } \\
\text { content }\end{array}$} \\
\hline & & & & & & & \\
\hline \multirow{2}{*}{ Resistivity } & Q5 & -0.167 & -0.0083 & -3.574 & 5.993 & 0.76 & Average \\
\hline & Q10 & -0.157 & -0.0079 & -3.383 & 5.637 & 0.73 & $20 \mathrm{~mm}$ \\
\hline \multirow{2}{*}{ Capacitive } & $\mathbf{A E}$ & 1.037 & 0.0739 & 33.30 & -8.559 & 0.72 & $10 \mathrm{~mm}$ \\
\hline & LE & 0.612 & 0.0757 & 28.92 & -3.527 & 0.78 & Average \\
\hline \multirow{7}{*}{ GPR } & Epsilon & 0.246 & 0.0519 & 9.628 & 1.600 & 0.85 & $20 \mathrm{~mm}$ \\
\hline & Velocity & -0.105 & -0.026 & -3.397 & 13.45 & 0.89 & $20 \mathrm{~mm}$ \\
\hline & Log(peak-to- & -0.0125 & -0.0007 & -0.763 & -0.077 & 0.77 & $20 \mathrm{~mm}$ \\
\hline & peak) & & & & & & \\
\hline & Ampl CMP & -0.0015 & -0.0003 & -0.105 & -0.0189 & 0.73 & $20 \mathrm{~mm}$ \\
\hline & Ampl Off.-L & -0.0070 & -0.0009 & -0.227 & 0.308 & 0.87 & Average \\
\hline & Time Off.-L & 0.0181 & 0.00235 & 0.5245 & 0.788 & 0.67 & $20 \mathrm{~mm}$ \\
\hline
\end{tabular}

229 The influence of chlorides on electrical resistivity is complex since the interstitial fluids 230 in concrete are naturally conductive. Fluid in concrete depends on the composition of 231 the cement and additions, so it is influenced by alkali content: the more alkali there is in 232 the pore water, the smaller is the influence of external fluid [21]. The real value for $R w$ 233 in the Archie's law is a composition of conductance of fluids from the concrete and 234 from external ingresses [24]. Numerous works present the relationship between 
235 electrical resistivity and chloride diffusivity [25-27]. The Nernst-Einstein relationship,

236 used to describe chloride ingress in concrete structure, could be simplified by taking the

237 ideal hypothesis of a constant value for the ion diffusivity, which would give:

$$
c_{i}=k \cdot\left(\frac{1}{R}\right)
$$

239 with $c_{i}$ the concentration of ion $\mathrm{i}$ in the pore water; $k$ a constant deduced from the

240 Nernst-Einstein relationship and associated with the gas constant, the absolute

241 temperature, the ionic valence, the Faraday constant, the ion transport number, and its

242 activity coefficient; and $R$ the electrical resistivity. Apart from ideal cases, the

243 complexity of interactions between concrete interstitial fluid and chlorides may explain

244 why there is no report on the electrical resistivity of concrete versus chloride content of

245 pore water.

246 To avoid any influence of the ranges of variation for indicators and measurement on the

247 coefficients of the laws, a supplementary step was performed in this study through the

248 normalization (from 0 to 1 ) of the ND measurements and the indicator values, in the

249 range of their respective values. This allows the techniques and the coefficients to be

250 compared amongst themselves. Concerning the three indicators, their ranges are the

251 following: [0- 0.36\% of dry concrete mass] for $\mathrm{Cl}^{-}$, [28-100\%] for $S_{\mathrm{r}}$ and [12.5-18.1\%]

252 for Poro.

253 In Table 4, while focusing on the indicators, the chloride content coefficient presents the

254 highest values for all the EM techniques, except for the "Time Offset-Large"

255 observable. The ND approaches, focused on the attenuation of the radar wave, the

256 capacitive and the resistivity techniques, remain the most sensitive to chloride content,

257 the "GPR log (peak-to-peak)" observable being twice as sensitive as the others.

258 Concerning the saturation rate, the ND techniques devoted to time or velocity of radar 
259 wave propagation are the most sensitive, slightly more than for the chloride content.

260 The difference between the capacitive technique and the GPR time or velocity can be

261 explained by the fact that the EM characteristics of civil engineering materials at the

262 frequencies used (very low GPR frequency band) are sensitive to both chloride and 263 water content [28], due to the predominant effect of interfacial polarization.

a)

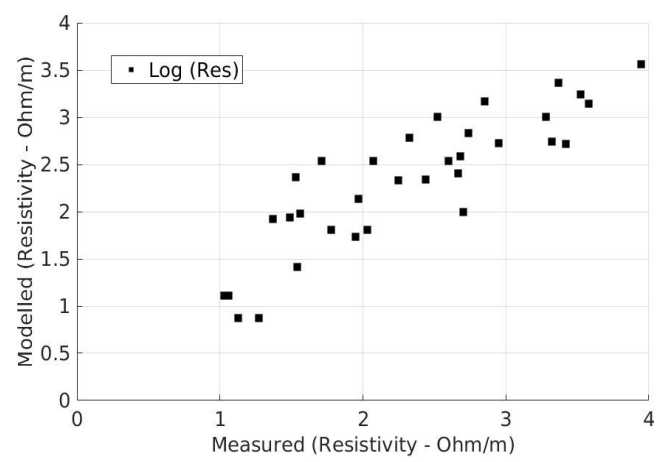

c)

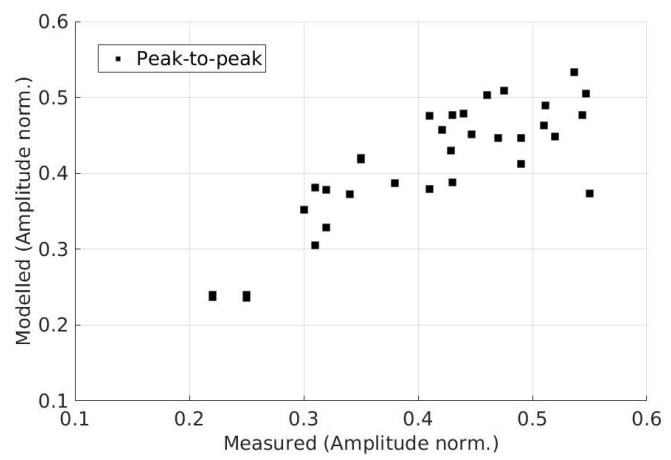

b)

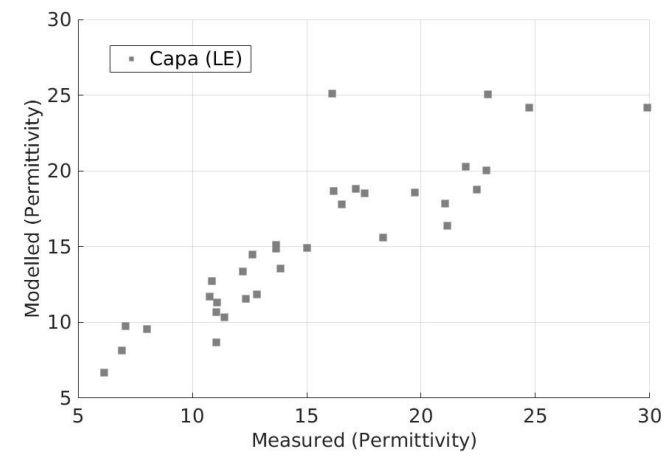

d)

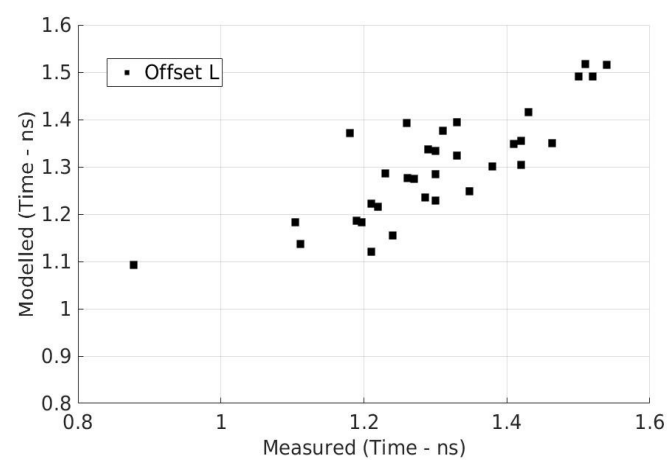

264 Fig. 2. Comparison of the measured and calculated observables for a) the resistivity technique

265 - quadripole $5 \mathrm{~cm} \mathrm{~b}$ ) the capacitive technique - large electrodes, c) the GPR Log(peak-to-peak) amplitude, d) the GPR amplitude (large offset), at their optimal configuration

Table 4. Coefficient of the multi-regressions of the ND normalized measurements performed in their optimal configuration of chloride content (corresponding to the greatest $\mathrm{a} / \sigma_{a}$ ) 


\begin{tabular}{llcccc}
\hline \multirow{2}{*}{ Resistivity } & Q5 & -0.32 & -0.20 & -0.45 & Average \\
& Q10 & -0.35 & -0.23 & -0.48 & $20 \mathrm{~mm}$ \\
\hline \multirow{2}{*}{ Capacitive } & AE & 0.18 & 0.17 & 0.38 & $10 \mathrm{~mm}$ \\
& LE & 0.14 & 0.23 & 0.45 & Average \\
\hline \multirow{3}{*}{ GPR } & Epsilon & 0.15 & 0.4 & 0.37 & $20 \mathrm{~mm}$ \\
& Velocity & -0.15 & -0.48 & -0.31 & $20 \mathrm{~mm}$ \\
& Log(peak-to- & -0.18 & -0.12 & -0.69 & $20 \mathrm{~mm}$ \\
& peak) & & & & \\
& Ampl CMP & -0.11 & -0.25 & -0.49 & $20 \mathrm{~mm}$ \\
& Ampl Off.-L & -0.23 & -0.39 & -0.49 & Average \\
& Time Off.-L & -0.20 & -0.39 & 0.28 & $20 \mathrm{~mm}$ \\
\hline
\end{tabular}

271 Finally, for the porosity estimation, the electrical techniques give the best performance.

272 This can be explained by the increase in connectivity of pores as the porosity increases,

273 which facilitates ionic displacement and thus the electric current, especially for

274 saturation degrees higher than $40 \%$.

275 This normalized study thus shows that all these EM techniques are capable of providing

276 information on the following indicators: chloride content, saturation rate and porosity, in

277 concrete mixes. Their sensitivity to these indicators encourages complementary use of

278 these ND techniques if we want to dissociate the indicators surveyed.

\section{On-site implementation and discussion}

281 The objective of the campaign described here is to estimate the uncertainty on the

282 values of indicators from ND measurements made at a real site in a tidal zone, using the

283 regressions studied above and the corresponding uncertainties (from the ND

284 measurement and from the regression). Given their high sensitivity to chlorides, three

285 techniques were considered for comparison, out of the three NDT families: resistivity,

286 capacity and GPR. By performing statistical calculations, this study, described below,

287 will quantify the influence of the ND measurements or the regressions on indicator 
288 estimation, from a structural engineering point of view. As the calibration was not 289 performed on the structure in question, only the uncertainties will be studied, and not

290 the absolute values, for which no reliability estimate can be made.

\section{4.1. Presentation of the site}

292 The chosen test site was a 15-year-old reinforced concrete wharf at the port of Saint293 Nazaire (France). A large ND campaign was carried out on the site in the framework of 294 the SENSO project, in which all the authors participated. The wharf, the ND techniques, 295 and the destructive analysis are accurately described in [15] and EM values in [29].

296 The structure tested was a precast reinforced concrete beam exposed to chloride ingress 297 in a tidal zone. The concrete mix used a CEM II/A 32.5PM cement with a water-to298 cement ratio of 0.46 , and included fly ash and siliceous aggregates as components. The 299 standard tests showed a 28-day compressive strength of about $36 \mathrm{MPa}$. Gas 300 permeability measurements on five cores gave values corresponding to a porosity in the 301 11-12\% range, and chloride profiles were also obtained from these cores.

302 The chloride profiles, presented in [15], show values of total chlorides per weight of dry 303 concrete of about $0.025 \%$ in the first $5 \mathrm{~mm}$, a maximum of $0.09+/-0.01 \%$ at $15+/-2 \mathrm{~mm}$ 304 and then a linear decrease to $0.03 \%$ at about $32 \mathrm{~mm}$.

Table 5. ND measurements performed on a concrete wharf at Saint-Nazaire (FR): averaged values and standard deviation per line between brackets

\begin{tabular}{lccccc}
\cline { 3 - 6 } & & Res Q5 & Capa LE & GPR velocity & GPR Ampl off L \\
\cline { 2 - 6 } Internal side & Line 1 & $3.52(0.399)$ & $5.97(0.374)$ & $11.53(0.163)$ & $0.51(0.0316)$ \\
& Line 2 & $3.41(0.366)$ & $6.21(0.384)$ & $11.46(0.217)$ & $0.51(0.0263)$ \\
& Line 3 & $3.35(0.283)$ & $6.25(0.369)$ & $11.47(0.224)$ & $0.50(0.0218)$ \\
\hline \multirow{3}{*}{ External side } & Line 1 & $3.36(0.323)$ & $6.91(0.133)$ & $11.05(0.282)$ & $0.45(0.0182)$ \\
& Line 2 & $3.41(0.365)$ & $6.95(0.254)$ & $10.94(0.271)$ & $0.44(0.0286)$ \\
& Line 3 & $3.45(0.431)$ & $6.94(0.189)$ & $11.04(0.246)$ & $0.45(0.0203)$
\end{tabular}




\begin{tabular}{lllll}
\hline NDT method S.D & 0.012 & 0.0003 & 0.003 & 0.0055
\end{tabular}

309 ND measurements were performed on each side of the beam - the external side exposed

310 to wind, rain and ocean spray, and the protected, internal side under the wharf deck - on

311 three horizontal lines. Thirty measurements were recorded per face, at the centre of the

312 reinforcement meshes. The ND values shown in Table 5 are the average of each line. An

313 ND procedure repeated several times at one point (centre of a reinforced mesh) in order

314 to find the standard deviation (S.D.) of each NDT method on the structure (last line of 315 table 5).

\section{4.2. Methodological approach}

318 Non-destructive measurements led to the determination of the observables, from which

319 the indicators were deduced through the inverse analysis of a specific relationship for 320 each technique, for instance Eq.1. During this process, uncertainty appeared at various 321 levels, mainly (Table 6 based on Eq.1):

322 - on the measurement (uncertainty on observable). This uncertainty was assessed 323 during the investigation of the structure by repeated measurements. For this 324 study, the measurement uncertainty is the standard deviation of repeated 325 measurements relative to the average value (in other words the Coefficient of 326 Variation CoV), given in terms of relative uncertainty;

327 - on the relationship between observable and indicator (model error). This error is 328 linked to the reliability of the calibration process. In this study, it corresponds to 329 the standard error value of the parameter considered, as assessed during the 330 linear regression calculation relative to the average value of the parameter (the 331 $\mathrm{CoV})$. 
332 The sensitivity analysis showing the effect of these various uncertainty levels on 333 diagnostic reliability is performed through a Monte Carlo simulation. It consists of 334 performing repeated sampling for a parameter described by its statistics (average and $335 \mathrm{CoV})$. The simulated population respects the same statistical distribution. Then from 336 each "simulated uncertain term" of the population, it is possible assess the uncertainty 337 propagating to the final result. For this study, and at each step, 1000 values were 338 simulated. According to the objective, the uncertainties could be simulated on different 339 parameters.

Table 6. Uncertainty levels on Eq.1

\begin{tabular}{lllll}
\hline parameter & for instance in Eq.1 & Symbol & uncertainty & uncertainty level \\
\hline Observable & Velocity GPR & $V_{G P R}$ & $+/-\delta V_{G P R}$ & measurement \\
law & Porosity coefficient & $a$ & $+/-\delta a$ & calibration \\
law & Saturation coefficient & $b$ & $+/-\delta b$ & calibration \\
law & Chloride content coefficient & $c$ & $+/-\delta c$ & calibration \\
law & Constant coefficient & $d$ & $+/-\delta d$ & calibration \\
indicator & Porosity & $P o r o$ & $+/-\delta P o r o$ & interpretation \\
indicator & Saturation rate & $S r$ & $+/-\delta S r$ & interpretation \\
indicator & Chloride content & $C l^{-}$ & $+/-\delta C l^{-}$ & interpretation \\
\hline
\end{tabular}

342 If the measurement uncertainty is considered, with the perfect regression model, $\delta V_{G P R}$

343 exists, and $\delta a, \delta b, \delta c, \delta d$ are equal to 0 . Respectively one thousand "measured" values

344 are considered (statistically correct), leading to the calculation of a thousand values for

345 Poro, $\mathrm{Sr}$ and $\mathrm{Cl}^{-}$after inversion. Thus the average values can be assessed for each

346 indicator as well as $\delta$ Poro, $\delta S r$, and $\delta C l$. If the measurement is considered as perfect

347 and the uncertainty is only on the regression model, $\delta V_{G P R}$ equals 0 , and $\delta a, \delta b, \delta c, \delta d$

348 exist. From measurements, and considering the thousand values each for a, b, c and d

349 (for the observable under consideration) to be statistically correct, a thousand values for 
350 poro, $\mathrm{Sr}$ and $\mathrm{Cl}^{-}$are assessed by inversion. Here again, average values are assessed for

351 indicators and for $\delta$ Poro, $\delta S r$, and $\delta \mathrm{Cl}^{-}$. Then, both approaches are studied and the 352 uncertainties on Poro, $S_{r}$ and $\mathrm{Cl}^{-}$are compared.

353 Moreover, the inversion process is carried out considering matrix calculations (Eqs 5 to

354 7) with $O$ the matrix of observables, $d$ the matrix containing the constant term of each

355 regression, $I$ the matrix of indicators, and $M$ the matrix of regression coefficients.

356 Inversion consists to of determining the matrix $[M]^{-1}$, inverse of $[M]$, thus leading to the 357 assessment of its determinant: $\operatorname{Det}(M)$.

358

$$
[O]-[d]=[I] x[M]
$$

359 with

$$
\left[\begin{array}{l}
\text { obs1 } \\
\text { obs2 } 2 \\
\text { obs33}
\end{array}\right]-\left[\begin{array}{l}
d 1 \\
d 2 \\
d 3
\end{array}\right]=\left[\begin{array}{l}
\text { indic } 1 \\
\text { indic } 2 \\
\text { indic } 3
\end{array}\right] \cdot\left[\begin{array}{lll}
a 1 & b 1 & c 1 \\
a 2 & b 2 & c 2 \\
a 3 & b 3 & c 3
\end{array}\right]
$$

361 Inversion consists of assessing $[\mathrm{M}]^{-1}$ in order to solve the following equation:

$$
[I]=([O]-[d]) x[M]^{-1}
$$

363 This problem is not solvable if $\operatorname{Det}(M)$ is equal to 0 , which would correspond to the 364 situation where the models have the same coefficients of regression. In this case, no 365 additional information would be provided by any NDT method compared with the 366 others. If Det(M) is very close to 0 , the calculation error will be very high. To overcome 367 this difficulty it is decided to consider uncertainties of indicators, namely $\delta P o r o, \delta S r$, 368 and $\delta \mathrm{Cl}^{-}$instead of the indicators themselves.

\subsection{Influence of types of uncertainty of NDT methods}

371 For this study, we considered the triplet: resistivity Q5, capa LE, and GPR velocity, 
372 chosen as the three techniques presenting the best relationship to chloride content in 373 each of the three NDT families (see $\mathrm{R}^{2}$ values in Table 3).

374 An overview of the results is given in the following tables (7, 8 and 9). Case 1 375 corresponds to ND values associated with their average standard deviation per line, 376 which includes a part of the material variability along the beam. Case 2 corresponds to 377 the standard deviation calculated at a measurement point, which corresponds to the 378 technique variability. Standard deviations decrease from roughly 40, 28, 23 and 2.4\% in 379 case 1 to $1.2,0.03,0.3$ and $0.55 \%$ in case 2 for res_Q5, capa_LE, GPR velocity and 380 GPR_Ampl_off_L, respectively.

381 The first observations in Tables 7 and 8 show that uncertainties on the regression 382 models lead to an unacceptable estimation of indicators. The models obtained from 383 laboratory experiments, which were not suited to Saint Nazaire wharf, are used. This is 384 made obvious by the negative values for chloride factors. So, the influence of model 385 error or measurement uncertainty is estimated by the error of indicator assessment and 386 not to by the value of the indicator. This implies that a calibration of the regression 387 models is necessary for each ND technique for every ND inspection on a new concrete 388 structure.

Table 7. Statistical inversions of the ND measurements, performed on a concrete wharf (Table 5), under the hypothesis of perfect regression models or perfect measurements and considering Case 1

\begin{tabular}{|c|c|c|c|c|c|}
\hline \multirow{2}{*}{\multicolumn{2}{|c|}{ Case 1}} & \multicolumn{2}{|c|}{ Perfect models (uncert. on meas.) } & \multicolumn{2}{|c|}{ Perfect measurements (uncert. on models) } \\
\hline & & Porosity & Sat & Porosity & Sat \\
\hline \multirow{3}{*}{ Int. side } & $\mathbf{L 1}$ & $14.3(29 \%)$ & $19.1(\mathbf{6 5 . 3 \% )}-0.025(\mathbf{3 0 6} \%)$ & $19.2(\mathbf{4 4 7 \% )}$ & $20.3(\mathbf{7 6 8 \% )}-0.17(\mathbf{1 5 6 9 \% )}$ \\
\hline & $\mathbf{L} 2$ & $15.2(\mathbf{2 6 . 2 \%})$ & $19.7(\mathbf{7 6 . 1 \%})-0.036(217 \%)$ & $20.4(447 \%)$ & $21.2(\mathbf{7 7 3 \% )}-0.19(\mathbf{1 4 6 0} \%)$ \\
\hline & L3 & 15.9 (19.1\%) & $18.1(\mathbf{7 9 . 2 \%})-0.046(\mathbf{1 4 3 \%})$ & $21.2(\mathbf{9 4 . 4 \% )}$ & $19.1(\mathbf{8 8 2} \%)-0.21(\mathbf{1 4 2 6 \% )}$ \\
\hline \multirow[t]{2}{*}{ Ext. side } & L1 & $15.2(\mathbf{2 4 . 1 \% )}$ & $17.4(\mathbf{4 6 \%})-0.060(\mathbf{1 2 7 \%})$ & $20.2(433 \%)$ & $42.2(\mathbf{3 8 8} \%)-0.22(\mathbf{1 2 5 7 \% )}$ \\
\hline & $\mathbf{L} 2$ & $14.7(27.2 \%)$ & $17.4(\mathbf{3 7 . 6 \% )}-0.070(\mathbf{1 1 4 \%})$ & $19.5(\mathbf{4 2 9 \% )}$ & 50.0 (321\%) -0.22 (1198\%) \\
\hline
\end{tabular}


\begin{tabular}{ll|lllll} 
L3 14.0 (33.3\%) 16.8 (40.4\%) & 0.044 (198\%) & 18.7 (433\%) & 44.5 (349\%) & $-0.19(\mathbf{1 3 5 1} \%)$
\end{tabular}

393 As inversions show similar results for the internal and the external sides, only the values

394 of the internal face are presented below.

Table 8. Statistical inversions of the ND measurements, performed on the internal side of the concrete wharf (Table 5), under the hypothesis of perfect regression models or perfect measurements and considering Case 2

\begin{tabular}{|c|c|c|c|c|c|c|c|}
\hline \multicolumn{2}{|c|}{ Internal side } & \multicolumn{3}{|c|}{ Perfect models (uncert. on meas.) } & \multicolumn{3}{|c|}{ Perfect measurements (uncert. on models) } \\
\hline & & Porosity & Sat & Cl- & Porosity & Sat & Cl- \\
\hline \multirow{3}{*}{ Case 2} & L1 & $14.4(0.9 \%)$ & $18.6(\mathbf{1 . 6 \% )}$ & $-0.026(\mathbf{8 . 3 \%})$ & $19.2(\mathbf{4 4 7 \% )}$ & $20.3(768 \%)$ & $-0.17(\mathbf{1 5 6 9 \% )}$ \\
\hline & L2 & $15.3(\mathbf{0 . 8 \%})$ & 19.4 (1.6\%) & $-0.038(5.5 \%)$ & $20.4(447 \%)$ & $21.2(773 \%)$ & $-0.19(\mathbf{1 4 6 0 \% )}$ \\
\hline & L3 & $15.9(\mathbf{0 . 8 \%})$ & $17.4(\mathbf{1 . 7 \%})$ & $-0.044(4.7 \%)$ & $21.2(\mathbf{9 4 . 4 \% )}$ & $19.1(\mathbf{8 8 2} \%)$ & $-0.21(\mathbf{1 4 2 6 \% )}$ \\
\hline
\end{tabular}

400 The analysis of Table 7 is mainly focused on the uncertainty values (percentage in bold

401 characters in brackets), and not on the values themselves, since the regression models 402 are not created on the surveyed concrete but on laboratory slabs. The first findings show 403 extremely high levels for $\delta$ Poro, $\delta S r$, and $\delta \mathrm{Cl}^{-}$in the case of uncertainty of models, in a 404 range ten times above those for the case of uncertainty of measurements.

405 The second point concerns the comparison of cases 1 and 2 when considering perfect 406 models. We can note similar values of indicators but a large difference in the uncertainty 407 values. Taking account of the variability of ND measurements from a large zone (Case 408 1) on the inversion induces results that are unacceptable because unreliable. We must 409 consider only the uncertainty of the NDT on this concrete mix (obtained from the 410 repetitive procedure on one representative local zone) rather than the integrated 411 uncertainty combining NDT and the variability of the material.

412 Finally, from a structural engineering point of view, the uncertainties on the indicators 
413 Poro, $\mathrm{Sr}$, and $\mathrm{Cl}^{-}$give rise to acceptable ranges when the hypothesis of perfect

414 regression models is maintained (if they can be designed on the concrete being

415 surveyed) and when the standard deviation of each ND technique is found on site.

416

\section{4.4. Influence of combination of observables}

418 The choice of the three techniques also has an influence on uncertainties of assessment.

419 We compare the results obtained when the techniques were selected on their own

420 reliability with respect to chloride variations (as in Section 3, techniques chosen on the

$421 \mathrm{R}^{2}$ value, see Table 3), or if the techniques were chosen according to their

422 complementarity (based on the assessment of the highest determinant value, see Eqs. 5

423 to 7).

424 The two cases are studied in Table 9, which shows the influence of observable

425 combination on the assessment of indicators. As expected, when the value of $\operatorname{Det}(M)$

426 decreases too much, the inversion process induces unacceptable uncertainties, as seen

427 for the triplet Techn. Res (Q5) / Capa (LE) / GPR ampl.

428

429 Table 9. Statistical inversions of the ND measurements, performed on the internal side of the

$430 \quad$ concrete wharf (Table 5), including either the GPR velocity or the GPR amplitude

\begin{tabular}{|c|c|c|c|c|}
\hline \multicolumn{2}{|c|}{ Perfect models (uncert. on meas.) } & Porosity & Sat & Cl- \\
\hline Techn. Res / Capa / GPR vel. & Line 1 & $14.4(\mathbf{0 . 9} \%)$ & $18.6(\mathbf{1 . 6 \%})$ & $-0.026(\mathbf{8 . 3 \%})$ \\
\hline Average S.D. per line & Line 2 & $15.3(\mathbf{0 . 8 \%})$ & $19.4(\mathbf{1 . 6 \%})$ & $-0.038(5.5 \%)$ \\
\hline Det $=\mathbf{- 0 . 0 4 6 4}$ & Line 3 & $15.9(\mathbf{0 . 8 \%})$ & $17.4(1.7 \%)$ & $-0.044(4.7 \%)$ \\
\hline Techn. Res / Capa / GPR ampl. & Line 1 & $4.7(4.5 \%)$ & $-849(\mathbf{1 . 9 \%})$ & $2.45(\mathbf{1 . 8 \%})$ \\
\hline Off. L & Line 2 & $4.2(5.0 \%)$ & $-965(\mathbf{1 . 6 \%})$ & $2.77(\mathbf{1 . 6 \%})$ \\
\hline Average S.D. per line & Line 3 & $3.0(6.9 \%)$ & $-1129(5.9 \%)$ & $3.23(\mathbf{1 . 3 \%})$ \\
\hline Det $=-\mathbf{0 . 0 0 0 9 2}$ & & & & \\
\hline
\end{tabular}


432 An explanation can be furnished by Figure 3, which shows the regression relations for 433 the two distinct NDT triplets (from Table 9) while focusing on chloride. Ideally, the 434 estimation of chloride content should be made by the intersection of the three 435 regressions. In both cases, there is no single intersection of the three curves. 436 Nevertheless, the uncertainty of the apparent solution (not exact since the calibration 437 does not correspond to the material under study) is represented by the band covered by 438 the three ranges of uncertainty for each of the observables.

439 The bandwidth of uncertainty on chloride content varies from less than 0.3 for the first 440 case (blue arrow in Fig. 3a), to more than 0.35 for the second case (blue arrow in Fig. 441 3b). The closer the three regressions intersect (the farther the determinant from Eq. 7 is 442 from 0) the less uncertainty there is. Then, for the second case, it is shown that both 443 resistivity and GPR amplitude have similar sensitivities to chloride (expressed by a 444 determinant very close to 0 ), and the third technique does not significantly improve the 445 assessment of indicator. For these two cases DET are -0.0464 , and -0.0009 , respectively.

a)

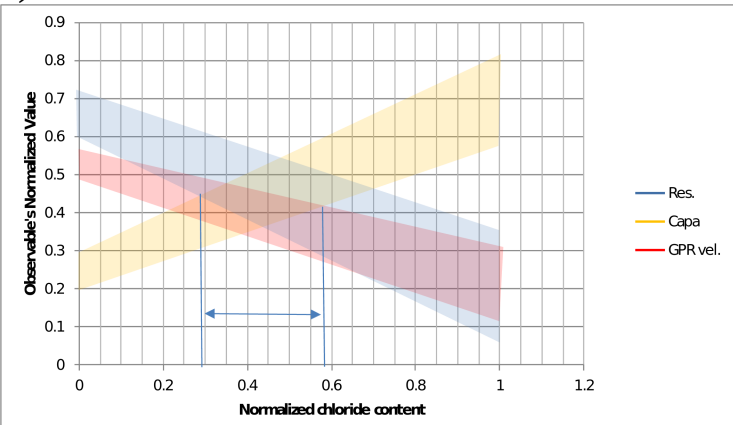

b)

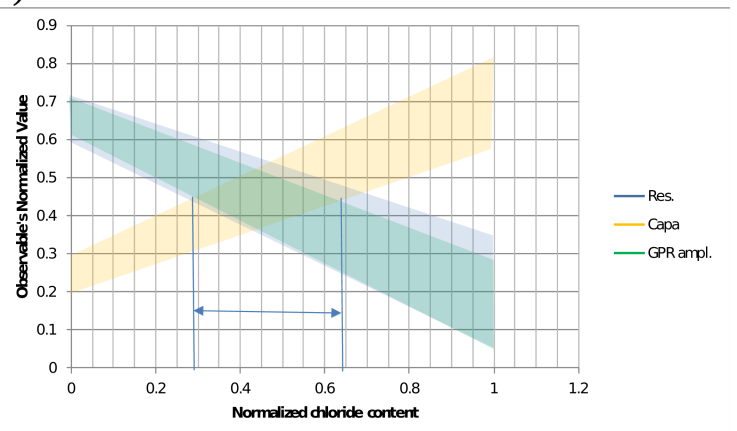

Fig. 3. Regressions of selected ND techniques (normalized values) versus chloride content for

448 the triplets a) Techn. Res (Q5) / Capa (LE) / GPR velocity and b) Techn. Res (Q5) / Capa (LE) / GPR ampl. The bandwidths correspond to the uncertainties of each regression. 
452 The question of the choice of three complementary techniques could be then based on 453 the determinant value. To test this approach, and having already chosen the resistivity 454 and capacitive techniques, a third NDT is chosen: GPR epsilon, which leads to $\operatorname{Det}(M)$ $455=0.0721$. The estimation of chloride content uncertainty with this new triplet (Fig. 4a) 456 is 0.35 . This value is in the range of the first results, proving that this approach is not 457 sufficient when working with EM techniques.

458 Going further in this study, we also tested this criterion by considering an ideal virtual 459 technique fairly perpendicular to the first two (Fig. 4b). The uncertainty level of this 460 technique was taken to be in the same range as the others. The result shows a chloride 461 content uncertainty decreasing to 0.15 . Finally, it should be noted that the uncertainty of 462 the ideal ND technique could strongly influence the uncertainty on indicators, even if 463 the intersection is quite perpendicular (that is to say, even if the determinant is high).

a)

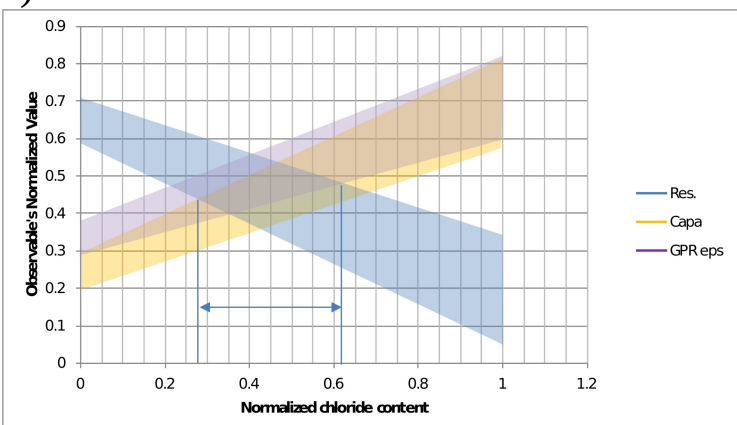

b)

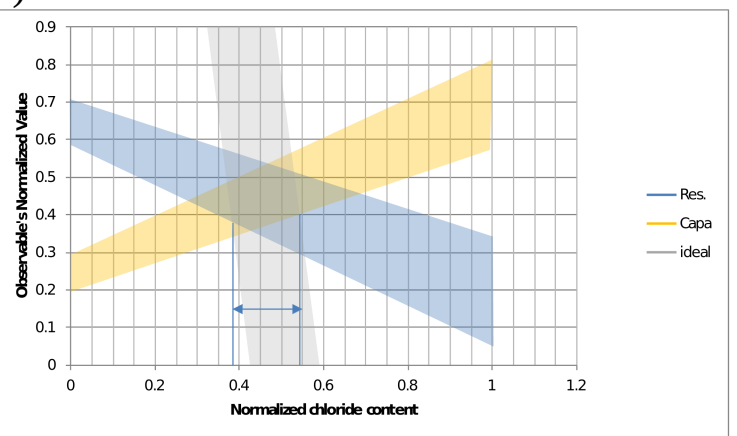

Fig. 4. Regressions of selected ND techniques (normalized values) versus chloride content for the triplets a) Techn. Res (Q5) / Capa (LE) / GPR eps and b) Techn. Res (Q5) / Capa (LE) / ideal techn. The bandwidths correspond to the uncertainties of each regression.

\section{Conclusion}

470 The results presented in this paper concern the implementation of different NDT 471 methods (using radar, capacitive and resistivity techniques) for the detection of 
472 chlorides in concrete. Three different concrete mixes were tested in the laboratory with 473 different levels of saturation and involving two concentrations of $\mathrm{NaCl}$. A multi-linear 474 regression, depending on the three indicators: chloride content, saturation rate and 475 porosity, was performed for each ND technique, under the hypothesis of averaged 476 indicator values without a depth gradient.

477 The results show that all the techniques devoted to attenuation measurements or the 478 resistivity are very sensitive to the presence of chlorides. This phenomenon is less 479 visible for the relative permittivity, as the frequency increases in the GPR frequency 480 band. Concerning the other two indicators, more than half of the ND techniques are less 481 than half as sensitive to them as to the chloride content.

482 Experiments on a real site in a marine environment have shown that it is necessary to 483 take two other indicators into account: the saturation rate and the porosity, to properly 484 estimate the chloride content through a multi-linear regression approach. A statistical 485 study was performed on the influence of the accuracy of ND measurements and the 486 model error on chloride content, from a structural engineering point of view.

487 The principal results show that:

488 - all the ND techniques must be calibrated on the structure actually surveyed,

489 - the combination of 3 techniques sensitive to chloride is not necessarily the best ND 490 triplet,

491 - the determinant of the regression equations considered as an indicator of reliability 492 (for chloride estimation), is not sufficient because it is sensitive to the 3 techniques, 493 - when considering a virtual ideal technique (the regression slope of which would be 494 "perpendicular" to those of the other techniques), the parametric study shows the 495 importance of the uncertainty of each technique in the estimation of the chloride 
496 content.

497 Finally, it is illusory to believe that it is possible to accurately estimate the chloride

498 content of a concrete structure using the hypothesis that all other indicators are spatially

499 constant. The paper has highlighted the present limitations of the various possible

500 approaches for chloride content assessment.

501

502 Acknowledgments

503 The French National Research Agency (ANR) is gratefully acknowledged for

504 supporting the ANR-PGCU SENSO project. This work is a contribution to COST action

505 TU1208 on “Civil engineering applications of GPR”.

506 Our thanks are extended to Susan Becker, a native English speaker, commissioned to 507 proofread the final English version of this paper.

508

509 Glossary

510 Chloride content: ratio (percentage) of the weight of total chloride (free and bound) to

511 the weight of dry concrete.

512 Durability indicator: property describing the concrete in term of durability and

513 performances (i.e. porosity, density, resistance, Young modulus, chloride content, 514 moisture...).

515 Indicator: generic term designating all durability indicators and more generally all the

516 properties involved in concrete durability

517 Multi-linear regression: approach of modeling the relationship between a dependent

518 variable (i.e. permittivity) and few conditioning variables (i.e. chloride content, 519 porosity...) using linear mathematical expression. 
520 ND observable: direct value (i.e. permittivity, resistivity...) or extracted value (i.e. wave

521 attenuation or velocity...) from non-destructive (ND) measurements.

522 Porosity: ratio (in percentage) of the volume of void to the total volume of material.

523 Saturation rate: ratio (in percentage) of a volume of fluid (interstitial solution for

524 concrete) to the total volume of voids inside concrete.

525 uncertainty: statistical expression of the dispersion of a result, associated to the 526 imperfect and/or unknown information. For an inverse process to predict a value (ie.

527 Chloride content), it can result from both imperfect measurement and imperfect model.

528 Variability: expression characterizing the effect of the natural unmastered variations of

529 the material properties at the measurement scale. It leads to the dispersion of the 530 measurement results which can be attributed to the object (material) being measured.

\section{References}

533 [1] Baroghel-Bouny V, Belin P, Maultzsch M, Henry D. AgNO3 spray tests 534 Advantages, weaknesses, and various applications to quantify chloride ingress into 535 concrete. Part 1: Non-steady-state diffusion tests in laboratory and exposure to $536 \quad$ natural conditions. Mater Struct 2007;40:759-781.

537 [2] Tutti K. Corrosion of steel in Concrete. Research Report 4.82. Swed Cem $538 \quad$ Concr Res Inst, Stockholm (SE), 1982.

539 [3] Kropp J, Alexander M. Non-destructive methods to measure ion migration. In: 540 RILEM Report 040 Non-destructive evaluation of the penetrability and thickness of 541 concrete cover. RILEM TC 189-NEC: State of the art report 2007;13-34.

542 [4] M. Torres-Luque M, Bastidas-Arteaga E, Schoefs F, Sánchez-Silva M, Osma 543 JF. Non-destructive methods for measuring chloride ingress into concrete: State-of- 
$544 \quad$ the-art and future challenges. Constr Build Mater 2014;68:68-81.

545 [5] Soutsos MN, Bungey JH, Millard SG, Shaw MR, Patterson A. Dielectric 546 properties of concrete and their influence on radar testing. NDT\&E Int $547 \quad 2001 ; 34(6): 419-25$.

548 [6] Laurens S, Balayssac JP, Rhazi J, Arliguie G. Influence of concrete moisture 549 upon radar waveform. Mater Struct 2002;35(248):198-203.

550 [7] Klysz G, Balayssac JP. Determination of volumetric water content of concrete 551 using ground-penetrating radar. Cem Concr Res 2007;37(8):1164-71.

552 [8] Hugenschmidt J, Loser R. Detection of chlorides and moisture in concrete 553 structures with ground penetrating radar. Mater Struct 2008;41(4):785-92.

554 [9] Kalogeropoulos A, Van der Kruk J, Hugenschmidt J, Busch S, Merz K. 555 Chlorides and moisture assessment in concrete by GPR full waveform inversion. $556 \quad$ Near Surf Geophys 2011;9(3):277-86.

557 [10] Villain G, Ihamouten A, du Plooy R, Palma Lopes S, Dérobert X. Use of 558 electromagnetic non-destructive techniques for monitoring water and chloride 559 ingress into concrete. Near Surf Geophys 2015;13:299-309.

560 [11] Loche JM, Lataste JF, Amiri O, Larget M, Tahlaiti M, Aït-Mokhtar A. 561 Evaluation of cover concrete and assessment of chloride ingress into cover concrete 562 by Non Destructive Testing. Part.I - Samples preparation - Porosity and resistivity 563 measurements. 1st Int Conf MEDACHS’08 Proc, Lisbon (PT), 2008.

564 [12] Dérobert X, Lataste JF, Loche JM, Villain G, Larget M, Aït-Mokhtar A, Amiri 565 O, Coffec O, Tahlaiti M, Durand O, Lu L, Abraham O. Evaluation of cover concrete 566 and assessment of chloride ingress into cover concrete by Non Destructive 567 Techniques. Part II - Comparison of NDT measurements and correlations. 1st Int 
569 [13] Balayssac JP, Laurens S, Arliguie G, Breysse D, Garnier V, Dérobert X, 570 Piwakowski B. Description of the general outlines of the French project SENSO 571 Quality assessment and limits of different NDT methods. Constr Build Mater $572 \quad$ 2012;35:131-8.

573 [14] Ploix MA, Garnier V, Breysse D, Moysan J. NDE data fusion to improve the 574 evaluation of concrete structures. NDT\&E Int 2011;44(5):442575 8,doi:10.1016/j.ndteint.2011.04.006.

576 [15] Sbartaï ZM, Breysse D, Larget M, Balayssac JP. Combining NDT Techniques 577 for Improving Concrete Properties Evaluation. Cem \& Conc Comp, 2012;34(6):725$578 \quad 33$.

579 [16] Villain G, Sbartaï ZM, Dérobert X, Garnier V, Balayssac JP. Durability 580 diagnosis of a concrete structure in a tidal zone by combining NDT methods: 581 laboratory tests and case study. Constr Build Mater 2012;37:893-903.

582 [17] Dérobert X, Iaquinta J, Klysz G, Balayssac JP. Use of capacitive and GPR 583 techniques for non-destructive evaluation of cover concrete. NDT\&E Int $584 \quad$ 2008;41(1):44-52.

585 [18] Chataigner S, Saussol JL, Dérobert X, Villain G. Temperature influence on 586 electromagnetic measurements of concrete moisture", Eur Journ Env \& Civil Eng 587 2015;19(4):482-95,http://dx.doi.org/10.1080/19648189.2014.960102.

588 [19] Lataste JF, Sirieix C, Breysse D, Frappa M. Electrical resistivity measurement 589 applied to cracking assessment on reinforced concrete structures in civil $590 \quad$ engineering. NDT\&E Int 2003;36(6):383-94.

591 [20] Lataste JF, de Larrard T, Benboudjema F, Semenadisse J. Study of electrical 
resistivity: variability assessment on two concretes: protocol study in laboratory and assessment on site. Eur Journ Env \& Civil Eng 2012;16(3-4):298-310.

594 [21] Hunkeler F. The resistivity of pore-water solution - a decisive parameter of 595 rebar corrosion and repair methods. Constr Build Mater 1996;10(5):381-9.

596 [22] Saleem M, Shameem M, Hussain SE, Maslehuddin M. Effect of moisture, 597 chloride, and sulfate contamination on the electrical resistivity of Portland Cement 598 Concrete. Constr Build Mater 1996;10(3):209-14.

599 [23] Sbartaï ZM, Laurens S, Balayssac JP, Arliguie A, Ballivy G. Ability of the 600 direct wave of radar ground-coupled antenna for NDT of concrete structures. $601 \quad$ NDT\&E Int 2006;39:400-7.

602 [24] McCarter WJ, Ezirim H, Emerson M. Properties in the cover zone :Water 603 penetration, sorptivity and ionic ingress. Mag Concr Res 1996;48(176):149-56.

604 [25] Andrade C, Andrea R, Rebolledo N. Chloride ion penetration in concrete: the 605 reaction factor in the electrical resistivity model. Cem Concr Comp 2014;47:41-6.

606 [26] Polder RB, Peelen WHA. Characterisation of chloride transport and 607 reinforcement corrosion in concrete under cyclic wetting and drying by electrical 608 resistivity. Cem Concr Res 2002;24:427-35.

609 [27] Sengul O. Used of electrical resistivity as an indicator for durability. Constr $610 \quad$ Build Mater 2014;73:434-41.

611 [28] Dérobert X, Villain G, Cortas R, Chazelas JL. EM characterization of 612 hydraulic concretes in the GPR frequency-band using a quadratic experimental 613 design. 7th Int Symp NDT-CE Proc, Nantes (FR), 2009.

614 [29] Balayssac JP, Laurens S, Lataste JF, Dérobert X. Evaluation of chloride 615 contamination in concrete by combining non destructive testing methods. 2nd Int 
616 Conf MEDACHS`10 Proc, La Rochelle (FR), 2010.

617

\section{Appendix}

619 Table A1. Saturation rate, porosity and total chloride content (by weight of dry concrete) for all 620 the concretes

\begin{tabular}{|c|c|c|c|c|c|c|c|c|c|}
\hline Sample & $\mathbf{N}^{\circ}$ & $\begin{array}{l}\text { Expected } \\
\text { Sat. Rate }\end{array}$ & $\begin{array}{c}\text { Porosity } \\
\text { (\%) }\end{array}$ & $\begin{array}{c}\text { Sat. rate } \\
\text { (\%) }\end{array}$ & $\begin{array}{c}\text { Total } \\
\text { chloride } \\
\text { at } 5 \mathrm{~mm}\end{array}$ & $\begin{array}{c}\text { Total } \\
\text { chloride } \\
\text { at } 10 \mathrm{~mm}\end{array}$ & $\begin{array}{c}\text { Total } \\
\text { chloride } \\
\text { at } 15 \mathrm{~mm}\end{array}$ & $\begin{array}{l}\text { Total } \\
\text { chloride } \\
\text { at } 20 \mathrm{~mm}\end{array}$ & $\begin{array}{c}\text { Total } \\
\text { chloride } \\
\text { average }\end{array}$ \\
\hline \multirow{11}{*}{ G8 } & 1 & \multirow{3}{*}{40} & 18.1 & 28.8 & 0.00 & 0.00 & 0.00 & 0.00 & 0.00 \\
\hline & 2 & & 18.1 & 33.1 & 0.08 & 0.07 & 0.06 & 0.04 & 0.06 \\
\hline & 3 & & 18.1 & 35.7 & 0.34 & 0.31 & 0.25 & 0.24 & 0.29 \\
\hline & 4 & \multirow{3}{*}{80} & 18.1 & 68.1 & 0.00 & 0.00 & 0.00 & 0.00 & 0.00 \\
\hline & 5 & & 18.1 & 75.4 & 0.11 & 0.11 & 0.11 & 0.11 & 0.11 \\
\hline & 6 & & 18.1 & 75.8 & 0.26 & 0.22 & 0.21 & 0.23 & 0.23 \\
\hline & 7 & \multirow{5}{*}{100} & 18.1 & 100.0 & 0.00 & 0.00 & 0.00 & 0.00 & 0.00 \\
\hline & 8 & & 18.1 & 99.1 & 0.14 & 0.08 & 0.07 & 0.08 & 0.10 \\
\hline & 9 & & 18.1 & 99.8 & 0.14 & 0.08 & 0.07 & 0.08 & 0.10 \\
\hline & 10 & & 18.1 & 99.6 & 0.39 & 0.34 & 0.34 & 0.32 & 0.34 \\
\hline & 11 & & 18.1 & 100.0 & 0.39 & 0.34 & 0.34 & 0.32 & 0.34 \\
\hline \multirow{11}{*}{ G3 } & 12 & \multirow{3}{*}{40} & 15.5 & 28.7 & 0.00 & 0.00 & 0.00 & 0.00 & 0.00 \\
\hline & 13 & & 15.5 & 36.2 & 0.05 & 0.06 & 0.06 & 0.06 & 0.06 \\
\hline & 14 & & 15.5 & 39.1 & 0.19 & 0.16 & 0.14 & 0.13 & 0.15 \\
\hline & 15 & \multirow{3}{*}{80} & 15.5 & 70.7 & 0.00 & 0.00 & 0.00 & 0.00 & 0.00 \\
\hline & 16 & & 15.5 & 79.6 & 0.24 & 0.10 & 0.06 & 0.09 & 0.12 \\
\hline & 17 & & 15.5 & 78.1 & 0.46 & 0.27 & 0.23 & 0.20 & 0.29 \\
\hline & 18 & \multirow{5}{*}{100} & 15.5 & 100.0 & 0.00 & 0.00 & 0.00 & 0.00 & 0.00 \\
\hline & 19 & & 15.5 & 97.8 & 0.21 & 0.20 & 0.18 & 0.14 & 0.18 \\
\hline & 20 & & 15.5 & 99.8 & 0.21 & 0.20 & 0.18 & 0.14 & 0.18 \\
\hline & 21 & & 15.5 & 100.0 & 0.42 & 0.35 & 0.35 & 0.36 & 0.37 \\
\hline & 22 & & 15.5 & 100.0 & 0.42 & 0.35 & 0.35 & 0.36 & 0.37 \\
\hline \multirow{11}{*}{ G1 } & 23 & \multirow{3}{*}{40} & 12.5 & 33.6 & 0.00 & 0.00 & 0.00 & 0.00 & 0.00 \\
\hline & 24 & & 12.5 & 33.7 & 0.10 & 0.07 & 0.06 & 0.05 & 0.07 \\
\hline & 25 & & 12.5 & 41.2 & 0.16 & 0.14 & 0.09 & 0.08 & 0.12 \\
\hline & 26 & \multirow{3}{*}{80} & 12.5 & 71.7 & 0.00 & 0.00 & 0.00 & 0.00 & 0.00 \\
\hline & 27 & & 12.5 & 77.8 & 0.06 & 0.06 & 0.05 & 0.05 & 0.05 \\
\hline & 28 & & 12.5 & 76.2 & 0.18 & 0.13 & 0.17 & 0.15 & 0.16 \\
\hline & 29 & \multirow{5}{*}{100} & 12.5 & 100.0 & 0.00 & 0.00 & 0.00 & 0.00 & 0.00 \\
\hline & 30 & & 12.5 & 100.0 & 0.17 & 0.12 & 0.08 & 0.07 & 0.11 \\
\hline & 32 & & 12.5 & 99.6 & 0.17 & 0.12 & 0.08 & 0.07 & 0.11 \\
\hline & 32 & & 12.5 & 100.0 & 0.37 & 0.25 & 0.19 & 0.17 & 0.25 \\
\hline & 33 & & 12.5 & 98.4 & 0.37 & 0.25 & 0.19 & 0.17 & 0.25 \\
\hline
\end{tabular}


Table A2. ND measurements

\begin{tabular}{|c|c|c|c|c|c|c|c|c|c|c|}
\hline \multirow[t]{2}{*}{ Sample } & \multirow[t]{2}{*}{$\mathbf{N}^{\circ}$} & \multirow{2}{*}{$\begin{array}{c}\text { Capa } \\
\text { (LE) } \\
(-)\end{array}$} & \multirow{2}{*}{$\begin{array}{c}\text { Capa } \\
\text { (ME) } \\
(-)\end{array}$} & \multirow{2}{*}{$\begin{array}{c}\text { Log (Res } \\
-5 \mathrm{~cm}) \\
(\Omega . \mathrm{m})\end{array}$} & \multirow{2}{*}{$\begin{array}{c}\text { Log (Res } \\
-10 \mathrm{~cm}) \\
(\Omega . \mathrm{m})\end{array}$} & \multirow{2}{*}{$\begin{array}{c}\text { GPR } \\
\text { velocity } \\
\text { (cm/ns) }\end{array}$} & \multirow{2}{*}{$\begin{array}{c}\text { GPR pic- } \\
\text { pic } \\
(-)\end{array}$} & \multirow{2}{*}{$\begin{array}{c}\text { Log(GPR } \\
\text { att.) } \\
(-)\end{array}$} & \multirow{2}{*}{$\begin{array}{c}\text { GPR } \\
\text { Ampl } \\
\text { (D4) - (-) }\end{array}$} & \multirow{2}{*}{$\begin{array}{c}\text { GPR OD } \\
\text { (D4) } \\
\text { (ns) }\end{array}$} \\
\hline & & & & & & & & & & \\
\hline \multirow{11}{*}{ G8 } & 1 & 7.07 & 7.34 & 3.32 & 2.97 & 11.35 & 0.543 & -0.054 & 0.154 & 1.104 \\
\hline & 2 & 12.82 & 16.34 & 2.60 & 2.73 & 10.71 & 0.520 & -0.055 & 0.165 & 1.220 \\
\hline & 3 & 17.53 & 22.64 & 1.95 & 1.94 & 10.00 & 0.320 & -0.066 & 0.100 & 1.330 \\
\hline & 4 & 10.84 & 12.31 & 2.67 & 2.35 & 9.77 & 0.447 & -0.063 & 0.115 & 1.261 \\
\hline & 5 & 21.14 & 24.11 & 1.37 & 1.36 & 9.23 & 0.310 & -0.077 & 0.071 & 1.410 \\
\hline & 6 & 22.86 & 25.36 & 1.54 & 1.56 & 9.11 & 0.310 & -0.095 & 0.045 & 1.430 \\
\hline & 7 & 13.67 & 15.50 & 1.97 & 1.80 & 8.89 & 0.429 & -0.065 & 0.104 & 1.463 \\
\hline & 8 & 16.53 & 19.44 & 2.03 & 2.10 & 8.57 & 0.410 & -0.084 & 0.052 & 1.260 \\
\hline & 9 & 21.05 & 23.44 & 1.78 & 1.78 & 8.60 & 0.320 & -0.084 & 0.049 & 1.330 \\
\hline & 10 & 22.93 & 37.65 & 1.13 & 1.16 & 7.87 & 0.220 & -0.088 & 0.028 & 1.540 \\
\hline & 11 & 16.12 & 17.26 & 1.27 & 1.17 & 7.88 & 0.250 & -0.105 & 0.023 & 1.510 \\
\hline \multirow{11}{*}{ G3 } & 12 & 6.92 & 7.52 & 3.58 & 3.25 & 11.01 & 0.547 & -0.058 & 0.181 & 1.112 \\
\hline & 13 & 11.39 & 13.15 & 2.74 & 2.83 & 10.67 & 0.510 & -0.053 & 0.155 & 1.190 \\
\hline & 14 & 12.20 & 16.08 & 1.71 & 1.72 & 10.76 & 0.350 & -0.052 & 0.166 & 1.300 \\
\hline & 15 & 11.08 & 12.58 & 2.32 & 2.04 & 9.56 & 0.430 & -0.071 & 0.142 & 1.285 \\
\hline & 16 & 18.34 & 21.68 & 1.53 & 1.52 & 9.43 & 0.350 & -0.073 & 0.082 & 1.380 \\
\hline & 17 & 21.95 & 23.29 & 1.49 & 1.35 & 9.03 & 0.300 & $-0.080-$ & 0.056 & 1.420 \\
\hline & 18 & 13.85 & 16.19 & 2.07 & 1.84 & 8.61 & 0.421 & 0.061 & 0.120 & 1.420 \\
\hline & 19 & 19.72 & 19.71 & 2.70 & 2.74 & 8.64 & 0.550 & -0.101 & 0.041 & 1.180 \\
\hline & 20 & 22.43 & 24.34 & 1.56 & 1.57 & 8.39 & 0.340 & -0.092 & 0.040 & 1.310 \\
\hline & 21 & 29.90 & 27.76 & 1.03 & 1.03 & 7.45 & 0.220 & -0.125 & 0.012 & 1.520 \\
\hline & 22 & 24.74 & 23.17 & 1.06 & 1.02 & 7.72 & 0.250 & -0.121 & 0.017 & 1.500 \\
\hline \multirow{11}{*}{ G1 } & 23 & 6.15 & 5.86 & 3.94 & 3.38 & 11.27 & 0.537 & -0.064 & 0.158 & 0.878 \\
\hline & 24 & 11.04 & 12.38 & 3.37 & 3.50 & 10.23 & 0.460 & -0.060 & 0.129 & 1.210 \\
\hline & 25 & 11.04 & 13.52 & 2.85 & 2.82 & 10.20 & 0.440 & -0.049 & 0.155 & 1.240 \\
\hline & 26 & 8.02 & 7.59 & 3.52 & 3.22 & 10.30 & 0.475 & -0.066 & 0.166 & 1.196 \\
\hline & 27 & 12.35 & 12.96 & 2.52 & 2.51 & 9.97 & 0.410 & -0.059 & 0.129 & 1.210 \\
\hline & 28 & 12.62 & 14.09 & 2.68 & 2.64 & 9.95 & 0.490 & -0.060 & 0.126 & 1.270 \\
\hline & 29 & 10.75 & 11.17 & 3.28 & 3.06 & 9.55 & 0.511 & -0.057 & 0.155 & 1.347 \\
\hline & 30 & 15.02 & 15.85 & 3.42 & 3.52 & 9.76 & 0.490 & -0.067 & 0.115 & 1.230 \\
\hline & 32 & 13.65 & 15.40 & 2.95 & 3.01 & 9.76 & 0.470 & -0.067 & 0.115 & 1.300 \\
\hline & 32 & 17.14 & 17.75 & 2.25 & 2.27 & 9.36 & 0.380 & -0.071 & 0.079 & 1.290 \\
\hline & 33 & 16.19 & 18.62 & 2.44 & 2.41 & 9.58 & 0.430 & -0.070 & 0.096 & 1.300 \\
\hline
\end{tabular}

